\title{
Awareness of HIV/AIDS among transportation staff linked to Dharan municipality, Sunsari, Nepal
}

\author{
S Shrestha ${ }^{1}$, T Shah ${ }^{1}$, S Lamsal ${ }^{1}$, GN Mandal ${ }^{2}$ \\ Department of Community Health Nursing ${ }^{1}$, Department of Medical-Surgical Nursing ${ }^{2}$ \\ B.P. Koirala Institute of Health Sciences, Dharan, Nepal
}

\begin{abstract}
Background: Transportation workers are the high risk group for HIV/AIDS infection because they travel frequently; often engage in unsafe sex to reduce their loneliness. The UN predicts 68 million more deaths over the next twenty years if efforts on prevention are not increased. Objective: To assess the level of awareness and to find out association between awareness about HIV/AIDS and selected variables. Method: Cross sectional, descriptive study with sample of 197 staff (driver, conductor and helper) of buses and trucks of Dharan city. Purposive sampling technique was used with pretested semi structured questionnaire. Result: The median age of drivers was 28.5, conductor's 28 and helper's 21 years. Most of them (84.2\%) were within the age group of $15-34$ years. Majority stays (77.2\%) less than a week away from home. Almost $93 \%$ had heard about HIV/AIDS. Still $55.8 \%$ \& $32.5 \%$ believed HIV is transmitted by insect bite and having food together respectively. Eighty one percent believed that HIV/AIDS status of self should not be kept secret with sexual partner. More than (56.7\%) had first sexual exposure at the age of 19 or below. Maximum (77.4\%) had not used condom at first sexual intercourse. About 15.2\% has sex with CSWs. Among them 93.3\% were frequenting CSW for more than once. Forty percent had multi-partner. Conclusion: Staff of bus \& truck of Dharan showed as the awareness level increased, risk taking behavior decreased and attitude became more positive among the transportation staff.
\end{abstract}

Key words: Conductor, driver, HIV/AIDS, helper, transportation staff

\footnotetext{
Address for correspondence

Sharmila Shrestha

Senior Instructor

Department of College of Nursing

B.P. Koirala Institute of Health Sciences, Dharan

Email: bisusaru@yahoo.com
} 


\section{Introduction}

A large number of people in the Nepal are unaware of HIV infection, even though aggressive awareness program regarding HIV/AIDS from different stakeholders have been launched, the case of HIV/AIDS are increasing rapidly and the HIV infection is highest among the high risk groups, such as truckers, sex workers, migrant workers, policeman/army personnel, businessman etc. The UN predicts 68 million more deaths over the next twenty years unless efforts at preventive and treatments are increased. ${ }^{1}$

Acquired Immune Deficiency Syndrome (AIDS) was first recognized internationally in 1981. South Asia has more than 20 per cent of the world's population facing an HIV epidemic with an estimated 5.5 to 6 million people have been HIV infected. ${ }^{1}$ The first case of AIDS in Nepal was reported in 1988. In Nepal as per 15 July 2009 a cumulative total cases of 14320 HIV infections, including 2493 AIDS cases and 534 deaths from AIDS, have been reported. ${ }^{2}$

The association between migration, mobility, and infection with the human immunodeficiency virus (HIV) has been documented almost since the beginning of the epidemic of acquired immunodeficiency syndrome (AIDS). Early studies suggested that rates of HIV infection amongst people who had moved within or between countries were higher than amongst those who did not travel. ${ }^{3}$ Result from a study conducted by Niraula S.R in Sunsari, Dharan indicated none of the drivers were graduated and very few (1.4\%) were educated up to intermediate. Trend of poly marriage was common in low educational category. It was found that the drivers, who had attitude to have multiple sex partners, were nearly 4 times more likely to visit commercial sex workers. ${ }^{4}$

One interventional study conducted by Sharma $M$ in adults in Institute of Medicine, Kathmandu, the mean scores on knowledge about the mode of transmission of HIV/AIDS as a whole in the pre-test and the post-test were found 6.37 and 13.92 with the standard deviations of 4.85 and 1.63 respectively. Further the difference in knowledge as a whole between pre-test and the post-test was found highly significant. ${ }^{5}$

A study of Lahore, Pakistan highlights that Truck drivers are more vulnerable to HIV infection, because they travel a lot (day and night), often out of homes for months. They are free from social pressures of the family. Unsafe sex with commercial sex workers and fellow crew members is not uncommon. ${ }^{6}$ A survey of truck drivers visiting sex workers at truck stops in KwaZulu-Natal, South Africa, indicated that $37 \%$ of all men always stopped for sex along the route, $29 \%$ reported never using condoms with sex workers. ${ }^{7}$ 


\section{Methods}

Study design: This was a cross sectional study completed in the year 2012. In this study 197 worker of bus and truck (driver, conductor and helper) of Dharan city, Nepal, were interviewed on nonrandom basis, using purposive sampling technique.

Statistics: Chi square test was used to find out statistical significance between two or more categorical data i.e. selected demographic variables individually applied with knowledge, attitude and risk taking behavior. Spearman Rank Correlation test was applied to identify overall correlations between knowledge, attitude and risk taking behavior. Level of significance was set at $<0.05$.

Instrument: Semi structured questionnaire with both close and open ended questions were prepared consisting following parts:

1. Questionnaire Related to Measurement of Knowledge Regarding HIV/AIDS. There were total 24 questions. The answer which is true is scored 1 otherwise 0 . Maximum obtainable score was 25 and minimum was 0 . Obtained score was converted into percentage and their correlation with other variables was studied along with it was graded as: a) $\geq 60 \%=$ Adequate knowledge $\quad$ b) $<60 \%$ $=$ Inadequate knowledge

2. Questionnaire Related to Measurement of Attitude pertaining to HIV/AIDS. The three point likert scale was used consisting total 6 statements. Maximum obtainable score was 6 and minimum was 0 and was graded as: a) $\geq 60 \%=$ High Positive attitude b) $<60 \%=$ Low positive attitude.

3. Measurement of risk taking behavior concerning HIV/AIDS. There were total 8 questions. Every answer which gave sense of risk taking behavior was given 0 marks and 1 was given for every non risky behavior answer. The marking was increased +1 as the response was more close to complete non risk taking behavior pertaining to HIV/AIDS. Maximum obtainable score was 12 and minimum was 0 . Obtained score was graded as: a) $\geq 60 \%=$ Low risk $\quad$ b) $<60 \%=$ High risk

4. Finally individual score of knowledge, attitude and practice was summed to find out level of awareness and used statistical correlation with other variables. Total obtainable score was 43 and minimum 0 which was graded as: a) $\geq 60 \%=$ adequately aware b) $<60 \%=$ inadequately aware

\section{Results}

In the present study total respondents were 197 (78 drivers, 43 conductors \& 76 helpers). Age range was 15 to 66 years old, in which driver's median age 28.5, IQR: 24-33, conductor's 28, IQR: 22-35 and helper's 21, IQR: 19-26. Out of total staff, almost all 
(94.4\%) were literate. Among literate, more than $(58.0 \%)$ of respondents had formal education up to secondary level. Nearly two third $(61.4 \%)$ were married and among unmarried $56.6 \%$ had premarital sexual intercourse. Majority (77.7\%) accommodating with family and rest (22.3\%) were staying along. Most (88.8\%) of them earn more than Rs. 2700 per month. More than half $(50.3 \%)$ had worked in transportation sector for more than five years. More than half $(51.3 \%)$ of the respondents were working for 5-11 hours per day and around $49 \%$ were working for $12-18$ hours per day.

Almost $93.0 \%$ of respondents had heard about HIV/AIDS. Around $78.2 \%$ respondents knew that HIV/AIDS is sexually transmitted infection. Most (54.9\%) of them mentioned that they heard from media like radio, television etc. More than half $(52.7 \%)$ of the respondents didn't know difference between HIV and AIDS. More than one third (37.6\%) of them said that there is no treatment available. Only $17.8 \%$ had tested their blood for HIV and rest $82.2 \%$ did not know their HIV related status. There was $1 \% \quad(n=2)$ respondent found to be HIV positive. Only $1.5 \%$ had heard about $\mathrm{CD}_{4}$ count.
Majority (84.8\%) of respondents said transmission of HIV/AIDS is from unsafe sex, $55.8 \%$ said from insect bite and $32.5 \%$ believed transmission by having food together. More than two third (81.7\%) believed that HIV/AIDS can be prevented by consistent with one faithful partner. Majority (81.7\%) knew that HIV can be prevented by using condom in every sexual intercourse. Eighty seven percent knew that prevention can be done by avoiding sharing of infected syringes. Regarding attitude of the respondents, $72.0 \%$ were ready to work with people living with HIV/AIDS (PLWHA), 73.6\% ready to shake hand, $81.2 \%$ were against the believe that HIV status should keep secret with sexual partner \& $75.6 \%$ agreed that PLWHA can be a friend.

There were 164 respondents of sexual exposure. Among them 19 or below years of age that came into sexual contact first times in their life were $56.7 \%$. Respondents of $15.2 \%$ had sexual contact with commercial sex workers (CSW). Among them 93.3\% had sexual intercourse with CSW for more than once and $26.7 \%$ had not used condom during sexual intercourse with them. Forty percent had multi-partner. On the whole, $91.0 \%$ of drivers, $97.7 \%$ conductor \& $85.5 \%$ helpers were adequately aware about HIV/AIDS. 
Table 1: Respondents knowledge on HIV/AIDS ( $n=197)$

\begin{tabular}{|l|l|c|l|c|}
\hline SN & \multicolumn{1}{|c|}{ Characteristics } & \multicolumn{3}{c|}{ Category } \\
\cline { 3 - 5 } & & Yes \% & No \% & Don't know (\%) \\
\hline 1 & Heard about HIV/AIDS & 92.9 & 17.1 & - \\
\hline 3 & HIV and AIDs is similar & 47.3 & 29.9 & 22.8 \\
\hline 7 & Healthy looking person may have HIV infection & 73.6 & 7.6 & 18.8 \\
\hline 8 & Treatment available for HIV/AIDS & 36.5 & 37.6 & 25.9 \\
\hline 9 & Heard about VCT & 16.8 & 83.2 & - \\
\hline 10 & Found HIV + ve & 1.0 & 99.0 & - \\
\hline 11 & Heard $\mathrm{CD}_{4}$ count & 1.5 & 96.5 & - \\
\hline
\end{tabular}

Table 2: Associations of demographic characteristics with level of knowledge on HIV/AIDS among the transportation staff $(n=197)$

\begin{tabular}{|l|c|c|c|}
\hline \multirow{2}{*}{\multicolumn{1}{|c|}{ Characteristics }} & \multicolumn{2}{|c|}{ Level of knowledge } & P value \\
\cline { 2 - 4 } & Adequate \% & Inadequate \% & \\
\hline Age (years) & 65.6 & 34.4 & \\
$15-24$ & 69.2 & 30.8 & 0.423 \\
$25-34$ & 68.4 & 31.6 & \\
$35-44$ & 77.0 & 23.0 & \\
$>45$ & 40.0 & 60.0 & \multirow{2}{*}{0.014} \\
\hline Caste & 67.2 & 32.8 & \\
Dalit & 76.0 & 24.0 & \\
Janajati & & 31.6 & 0.924 \\
Upper caste & 68.4 & 32.2 & \\
\hline Marital status & 67.8 & 20.0 & \multirow{2}{*}{0.089} \\
Unmarried & 80.0 & 34.2 & \\
Married & 65.8 & 40.0 & \\
\hline Education & 60.0 & & \\
Primary (1-5) & & & \\
Secondary (6-10) & & & \\
SLC \& above & &
\end{tabular}




\begin{tabular}{|l|c|c|c|}
\hline Income/day SRs.90 & 45.5 & 54.5 & $0.016^{*}$ \\
& 70.9 & 29.1 & \\
\hline Work & & & \\
Driver & 74.3 & 25.7 & $0.004^{*}$ \\
Conductor & 83.8 & 16.2 & \\
Helper & 52.6 & 47.4 & \\
\hline
\end{tabular}

p Chi-square test, *Significant at $<0.05$,

Table 3: Associations of demographic characteristics with level of attitude among the transportation staff towards people living with HIV/AIDS (PLWHA) $(n=197)$

\begin{tabular}{|c|c|c|c|}
\hline \multirow[t]{2}{*}{ Characteristics } & \multicolumn{2}{|c|}{ Level of attitude } & \multirow[t]{2}{*}{$P$ value } \\
\hline & High positive\% & Low positive $\%$ & \\
\hline \multicolumn{4}{|l|}{ Age (years) } \\
\hline $15-24$ & 79.3 & 20.7 & \multirow{4}{*}{0.273} \\
\hline $25-34$ & 71.8 & 28.2 & \\
\hline $35-44$ & 52.6 & 47.4 & \\
\hline$>45$ & 84.6 & 15.4 & \\
\hline \multicolumn{4}{|l|}{ Caste } \\
\hline Dalit & 46.7 & 53.3 & \multirow{3}{*}{$0.037^{*}$} \\
\hline Janajati & 74.8 & 25.2 & \\
\hline Upper caste & 79.4 & 20.6 & \\
\hline \multicolumn{4}{|l|}{ Marital status } \\
\hline Unmarried & 68.4 & 31.6 & \multirow[t]{2}{*}{0.148} \\
\hline Married & 77.7 & 22.3 & \\
\hline \multicolumn{4}{|l|}{ Education } \\
\hline Primary (1-5) & 73.3 & 26.7 & \multirow{3}{*}{0.355} \\
\hline Secondary(6-10) & 77.2 & 22.8 & \\
\hline SLC \& above & 65.0 & 35.0 & \\
\hline \multicolumn{4}{|l|}{ Income/day } \\
\hline$\leq$ Rs.90 & 54.5 & 45.5 & $0.026^{*}$ \\
\hline$>$ Rs.90 & 76.5 & 23.4 & \\
\hline
\end{tabular}




\begin{tabular}{|l|l|l|l|}
\hline Work & 83.3 & 16.7 & \\
Driver & 81.4 & 18.6 & $0.001^{*}$ \\
Conductor & 60.5 & 39.5 & \\
Helper & & \\
\hline
\end{tabular}

p Chi-square test, *Significant at $<0.05$,

Table 4: Associations of demographic characteristics with level of risk taking behavior of the respondents regarding HIV/AIDS ( $n=197$ )

\begin{tabular}{|c|c|c|c|}
\hline \multirow[t]{2}{*}{ Characteristics } & \multicolumn{2}{|c|}{ Level of risk taking behavior } & \multirow[t]{2}{*}{$P$ value } \\
\hline & High risk \% & Low risk \% & \\
\hline \multicolumn{4}{|l|}{ Age (years) } \\
\hline $15-24$ & 24.1 & 75.9 & \multirow{4}{*}{0.916} \\
\hline $25-34$ & 27.0 & 73.0 & \\
\hline $35-44$ & 21.0 & 79.0 & \\
\hline$>45$ & 23.1 & 76.9 & \\
\hline \multicolumn{4}{|l|}{ Caste } \\
\hline Dalit & 40.0 & 60.0 & \multirow{3}{*}{$0.001^{*}$} \\
\hline Janajati & 61.3 & 38.7 & \\
\hline Upper caste & 63.5 & 36.5 & \\
\hline \multicolumn{4}{|l|}{ Marital status } \\
\hline Unmarried & 55.3 & 44.7 & \multirow[t]{2}{*}{0.242} \\
\hline Married & 63.6 & 36.4 & \\
\hline \multicolumn{4}{|l|}{ Education } \\
\hline Primary(1-5) & 20.0 & 80.0 & \multirow{3}{*}{0.093} \\
\hline Secondar(6-10) & 23.7 & 76.3 & \\
\hline SLC \& above & 35.0 & 65.0 & \\
\hline \multicolumn{4}{|l|}{ Income/day } \\
\hline$\leq$ Rs.90 & 31.8 & 68.2 & \multirow[t]{2}{*}{0.424} \\
\hline >Rs.90 & 24.0 & 76.0 & \\
\hline \multicolumn{4}{|l|}{ Work } \\
\hline Driver & 64.1 & 35.9 & \multirow[t]{2}{*}{0.053} \\
\hline Conductor & 74.4 & 25.6 & \\
\hline
\end{tabular}




\begin{tabular}{|l|l|l|l|}
\hline Helper & 48.7 & 51.3 & \\
\hline
\end{tabular}

p Chi-square test, *Significant at $<0.05$,

Table 5: Overall correlation of awareness with knowledge, attitude and risk taking behavior

\begin{tabular}{|l|c|c|c|c|}
\hline \multirow{2}{*}{ Variables } & \multicolumn{2}{|c|}{ Knowledge } & \multicolumn{2}{c|}{ Attitude } \\
\cline { 2 - 5 } & r value & P value & r value & P value \\
\hline Attitude & $0.560^{* *}$ & 0.001 & - & - \\
\hline Risk behavior & -0.067 & 0.352 & $-0.193^{* *}$ & 0.007 \\
\hline
\end{tabular}

Spearman Rank Correlation, Significant at $<0.05$

\section{Discussion}

Various studies have been done in Nepal regarding awareness about HIV/AIDS particularly with drivers of bus, truck and taxi. Many studies ${ }^{10,11,12}$ nationally and internationally, have been done only with drivers for various purposes. Study with assistants of the bus and truck regarding HIV/AIDS awareness have not been found as needed. Investigator interpretively discusses the findings and ties together all the loose ends of the study as well as tries to fit with the trends of other's findings.

Almost every one (92.9\%) of respondents had heard about HIV/AIDS. The study is supported by S. Niraula carried out in 2000 $A D$ shows that $70.2 \%$ had heard about HIV/AIDS. ${ }^{4}$ A study of national demographic and health survey 2006 also indicated that over $90.0 \%$ of the men in Nepal have heard of AIDS. ${ }^{13}$ This represents a substantial increase since 2000 that awareness on HIV/AIDS is in the increasing trends. The study showed that major percentage (98.5\%) of helpers were aware than driver (91.0\%) and conductor (97.7\%). This provides the evidence to believe that a link existed between the level of awareness and their nature of work.

Majority of the respondents had adequate knowledge on mode of transmission and prevention of HIV/AIDS but in contrast, a study by Anwar Muhammad et.al. at Lahore depicts that a large number of respondents had no knowledge about the mode of transmission of AIDS, high risk groups, sign and symptoms of AIDS and causes of HIV/AIDS infections. ${ }^{6}$ About $55.0 \%$ of respondents mentioned that they have heard regarding HIV/AIDS from media like radio, 
television, news pater etc and rest $45 \%$ had heard from friends, school etc. The result of the study supported the research findings of Muhammad Anwar, 2005, mass media had the strongest effect on HIV/AIDS knowledge ${ }^{6}$ but in contrast, study of S. Niraula et.al. showed that driver considered radio a least important media of sex education. ${ }^{4}$ This is probably due to time gap between now and then because now a day radio broadcasts varieties of IEC materials. Therefore media has strong role in creating awareness on HIV/AIDS.

Present study shows that $48.7 \%$ respondent was working for 12-18 hours per day in the vehicles. This finding is supported by a study done by S. Balla et.al. at Gujrat which shows up to $40.5 \%$ of drivers used to drive 11 to 15 hours daily. This reflects that drivers at Dharan used to drive more hours than does driver of Gujrat. The hour of driving is indirectly linked with the tiredness and desire to search sexual outlet by the drivers. In one study it is coated that the truckers consider the conditions of their work, particularly exposure to hot weather and heat from the truck motors, to require release through sexual activity; also "tiredness caused by driving demands sexual relief". ${ }^{14}$

In the current study majority $(77.2 \%)$ of the respondents were remaining away from home for less than a week whereas $11.7 \%$ respondents were hanging about week to a month and small percentage (11.2\%) of respondents was staying more than a month away from home. In this study, comparatively less number of (22.9\%) respondents had stayed away from home for more than a week. This finding supported the research done by $\mathrm{S}$ Bhalla and $\mathrm{C}$ Somsundaram in Jamnagar that $27.5 \%$ of drivers remained away from their families for duration of more than one time at a time. ${ }^{8}$

In contrast, a study done in Africa shows that truckers remained long periods of time away from home. ${ }^{10}$ Similarly a study carried out by $\mathrm{FHI}$ shows that only $18.7 \%$ truckers remain away from home for a week otherwise majority $(81.3 \%)$ remained more than a week. ${ }^{15}$ From this one can assume that comparatively respondents of Dharan are short router and greater number of them do not get enough opportunity to hang outside for long period and involve in sexual activities as they come back home soon.

In the present study it shows monthly average income of the diver was Rs. 9999.9/month, conductor's Rs.9000/month and helper's Rs. 6000/month. A study of Anwar Muhammad et.al. at Lahore depicts that $77 \%$ of truck drivers had a monthly income of Rs. 6000 or less. This shows drivers of Dharan and Lahor had almost the same income per month when Rs. 6000 is converted into Nepali currency. A good number of respondents $(78.2 \%)$ knew that 
HIV/AIDS is sexually transmitted infection and remaining $21.8 \%$ were unaware. Therefore these remaining respondents were probably the most compelling part of the evidence to raise awareness. S. Balla et. al. concluded in their study that $53 \%$ of respondents considered sex as main route of transmission of HIV. $^{6}$ It clearly shows that there is increase in awareness level at present as compare to those days.

Majority (74\%) said that HIV virus could be found even in the healthy looking person. The result is supported by national demographic health survey (NDHS) report 2006 indicating relatively larger proportion of respondent ( $75 \%$ of men) is aware that a healthy-looking person can have the AIDS virus. ${ }^{13}$ Exactly similar percentage $(81.7 \%)$ of respondents had said it can also be prevented by using condom in every sexual intercourse. This result is supported by the report of World Bank ${ }^{17}$ compiled about recent 2007 survey of truckers in Pakistan revealed that $44.0 \%$ believed in efficacy of condoms in the prevention of HIV/STIs. Similarly S. Balla's et.al. study also quote that $70.7 \%$ considered condom as a protective measure for AIDS. ${ }^{8}$ This seems that greater percentage of respondents of Dharan were aware as compared to Pakistan and Jamnagar city, Gujrat.

Respondents who believed transmission of HIV/AIDS from unsafe sex were $84.8 \%$, from unscreened blood and sharing sharps (needle, syringe etc) were the same percentage (83.3\%). Majority (71.1\%) of them believed that it can be transmitted through pregnant mother to child as well. Still 33.0\% of respondents consider that it can be transmitted from insect bite and $17.8 \%$ thought that transmission can be from food sharing. A study of Anwar Muhammad et al. and Niraula S. et.al. supports the findings. ${ }^{6}$

There were 164 respondents of sexual exposure. Nearly half $(47.7 \%)$ of the respondents had agreed about the involvement in sexual intercourse during premarital period. Among them below or equal to 19 years of age who came into sexual contact first time in their life were $56.7 \%$ and remaining $43.3 \%$ had sexual intercourse after the age of 19 years. From this result one can assume that majority of the transport workers have sexual exposure at the tender age.

Similarly, out of 197 respondents $40.2 \%$ had multiple partners currently and among them $26.9 \%$ uses condom in every sexual act whereas $5.1 \%$ never use it and rest $1.5 \%$ mentioned they use as per situation; if they feel trust to each other, do not use and if not, uses it. A study depicts that truck drivers constitute a high risk group as far as the transmission of HIV/AIDS. Majority of HIV infection occurs in persons of young age 2145 years. Sexually more active and 
economically more productive. Multiple sex partners and sex with unknown person is very important factor for getting HIV infection. ${ }^{11} \mathrm{~A}$ recent study at Haidarabad, Andrapradesh by Dude Anne et. al. showed $15.3 \%$ of truck drivers report having multiple sexual partners in the past year. ${ }^{16}$

Out of 197 respondents $15.2 \%$ had sexual contact with commercial sex workers whereas most $(84.8 \%)$ of them had not. Among them $93.3 \%$ had sexual intercourse with CSW for more than one time. Nearly $27 \%$ had not used condom during sexual intercourse with CSW, the reasons they gave about not utilization condom were due to trust $(37.5 \%)$, not available at that time $(12.5 \%)$, don't like using (12.5\%), no satisfaction (37.5\%). Niraula S. et.al. explains that the drivers who visited to CSWs were $6.8 \%$. Out of them more than $57.0 \%$ of drivers did not use condom during intercourse. $^{4}$ In a 2007 survey in Bangaladesh, $82.5 \%$ of truckers have never used condoms with CSWs. ${ }^{17}$ This means compared to those days now a days the trend of using condom had been increased along but exposures with CSW has also increased.

\section{Conclusion}

In conclusion, majority of the transportation staffs were aware about HIV/AIDS. Staff having knowledge on HIV/AIDS had less risk behavior. The study finding showed that when knowledge of HIV/AIDS increased, staff were adequately aware as well as attitude was also increased. Economic status and risk behavior is highly significant i.e. those having well economic status had less risk behavior as compared to those having less income. Ninety one percent of drivers, $97.7 \%$ conductor and $85.5 \%$ helpers were adequately aware about HIV/AIDS.

\section{References}

1. UNAIDS/ WHO. AIDS epidemic update. December 2009:81-84 [AIDS Epidemic Update Archive]. Available from www.unaids.org.

2. Government of Nepal, Ministry of Health and Population, National Centre for AIDS and STD control. Available from http://www.ncasc.gov.np

3. IOM-UNAIDS reports. HIV and mobile workers; a review of risks and programme among truckers in West Africa. Sep 2005. Available from http://www.iom.int

4. Niraula S.R., Jha N. et al. Awareness and risk taking behaviors regarding sexually transmitted diseases among long distance drivers in a township of Dharan: A study from Nepal 2003. Indian J. Prev. Soc. Med. 34 (3\&4) .pp 136. Available from www.springerlink.com/index/e623n07r1 234q467.pdf 
5. Sharma M. Impact of educational intervention on knowledge regarding hiv/aids among adults.TUIOM nursing campus, Maharanjgunj, Kathmandu; 2008 Oct 13. JNHRC. 2010; 6 (2):104. Available from www.nepjol.info/index.php/JNHRC/articl e/viewPDFInterstitial/2213/2036

6. Anwar Muhammad, Chaudhry Muhammad, Naeem, Rizwan lqbal, Iffat Shabbir. Level of awareness about HIV/AIDS among truck drivers and their attitude towards persons with AIDS. Gomal Journal of Medical Sciences. 2005; 3(1)19-21. Available from www.gjms.com.pk/files/GJMS\%20.

7. Ramjee G, Gouws E. Prevalence of HIV among truck drivers visiting sex workers in KwaZulu-Natal, South Africa. 2001;29(1):44. Available from pdfs.journals.Iww.com/.../Prevalence_of _HIV_Among_Truck_Drivers_Visiting_S ex.8.pdf

8. S Bhalla and C Somasundaram Poster presentation; Long highways and risk of HIV/AIDS. International meeting of the institute of human virology Baltimore, USA. 2006;16(3): 17-21 16. Available from

www.retrovirology.com/content/3/S1/P9

9. Pradhan S. Nepal-Health: HIV Bomb Ticks Away on Boarder with India. Inter press news service (IPS); 1997 Jan 6
Available

from

http://www.aegis.com/news/ips/1997/IP 970101.html

10. Research Examines Role of Truck Drivers in HIV/AIDS Along Routes in Africa. IRIN/PLUS News [Newspaper on internet]. August 7, 2008; para, 1-2. Available from www.kaisernetwork.org/dailyreports/hiv

11. Singh, Gurinderbir, Dhaliwal, Devinder S; Kaur, Kulbir. Seroprevalence of HIV among truck drivers: Indian Journal of Community Medicine 1999; 24(4): 1537. Available from http://medind.nic.in/imvw/imvw6111.htm I

12. HIV/AIDS interventions in truck driver population in southern Africa: A review of literature and BCC materials, draft 03/02/2004. Available from www.aidsmark.org/.../HIV-AIDS

13. USAID, New ERA, Ministry of Health and Population. Nepal 2006 demographic and health survey; key findings; 2006.

14. Mahendra V.S., Verrma R., Pelto P., Pradhan S., Singh V., Rao A., and Vij T. "Context and dynamics of same sexual behaviors of long distance truckers in India: Findings from qualitative research." Population Council, New Delhi, India. 2006 
15. Environmental and social department, IFC, World Bank group. Good practice note; Dec 2002, number 2. Available from

http://www.ifc.org/wps/wcm/connect/6e aa6500488555c1b7f4f76a6515bb18/HI VAIDSEng.pdf?MOD=AJPERES\&CAC HEID=6eaa6500488555c1b7f4f76a651 $5 b b 18$

16. Dude Annie, Oruganti Ganesh, Vinod Kumar, Mayer Kenneth $\mathrm{H}$, Yeldandi, Vijay and Schneider John A. HIV
Infection, Genital Symptoms and Sexual Risk Behavior among Indian Truck Drivers from a Large Transportation Company in South India, J Glob Infect Dis. 2009; 1(1): 21-28. Para.14-15

17. World Bank global HIV/AIDS program. HIV/AIDS in the Transport Sector. Transport in south Asia. World Bank global HIV/AIDS program. Available from

http://go.worldbank.org/4FQQ5TN080. 